\title{
Managing hyperacute ischaemic stroke with interventional neuroradiology
}

An error occurred in the online version of this editorial by Alex M Mortimer and colleagues (BMJ 2012;344:e857, doi:10.1136/ bmj.e857). The third and fourth sentences of the sixth paragraph should read: "Recanalisation rates of $65-90 \%$ have been achieved using endovascular techniques, but favourable outcome (a modified Rankin score $\leq 2$ at three months) is achieved in only $25-60 \%$ of cases. ${ }^{6}$ This is probably because some patients are treated too late for recanalisation to be effective [not "for recanalisation to occur"]."

Cite this as: BMJ 2012;344:e1174

๑ BMJ Publishing Group Ltd 2012 